\title{
Design and Performance of a Novel Electrospray Interface
}

\author{
Mark H. Allen and Marvin L. Vestal \\ Vestec Corporation, Houston, 'Texas, USA
}

\begin{abstract}
In this work a new electrospray system has been developed which employs heat as a means of desolvation and requires no counterflow of heated gas. This article describes the operation and performance of this device, with particular emphasis on the differences between it and those described earlier. Results are presented that illustrate the dependence of signal intensity on ion source and spray chamber temperatures and on the composition and flow rate of mobile phase into the electrospray. Results on proteins electrosprayed from aqueous solutions are presented including a bacterial protease which has a tight tertiary structure. The ability to obtain fragmentation data by collisionally induced dissociation in the interface is also discussed. (J Am Soc Mass Spectrom 1992, 3, 18-26)
\end{abstract}

$\mathrm{T}$ The discovery by Fenn and co-workers [1] that electrospray could produce intense multiply charged ions from picomole quantities of proteins and other molecules has sparked yet another revolution in mass spectrometry. Recently, electrospray and ion spray [2] [pneumatically assisted electrospray or electrically assisted atmospheric pressure ionization (API)], have met with increasing interest. Many laboratories are now investigating their potential for interfacing liquid chromatography (LC) to a variety of mass analyzers, including quadrupoles, Fourier transform ion cyclotron resonance, ion trap, and magnetic sector. These efforts have been extensively reviewed $[3-6]$.

The capabilities of these new API techniques are just beginning to be explored. Briefly, electrospray provides efficient production of intact multiply charged molecular ions for a wide variety of biological polymers such as proteins and DNA fragments and also allows sensitive detection of low molecular weight polar species such as drugs and drug metabolites. It is now possible to determine accurately the molecular weights of modest-size proteins with accuracies of $0.01 \%$ or better $[7,8]$. Also, the suitability of electrospray for interfacing capillary electrophoresis [9] and microbore LC $[10,11]$ with mass spectrometry has been demonstrated.

In the present work a new electrospray system has been developed which is based in part on the concept used previously by Allen and Lewis [12] to interface an electrospray ion source to a magnetic sector instrument. This interface employs heat as a means of

Address reprint requests to Mark H. Allen, Vestec Corporation, 9299 Kirby Drive, Houston, TX 77054 desolvation and requires no counterflow of heated gas [13]. Its design and initial performance have been described previously [14]. It is the purpose of this article to describe this system more fully in terms of its operation and performance, with particular emphasis on the differences between this system and those described earlier by others.

\section{Experimental}

The electrospray interface developed in this work was installed on a Vestec model 201 single quadrupole mass spectrometer (Vestec Corp., Houston, TX) fitted with a $10-\mathrm{kV}$ conversion dynode and a $\mathrm{m} / z 2000$ mass range. Direct infusion of sample was performed by a SAGE syringe pump (Orion Research), and flow injection experiments employed a Phoenix 20 microLC pump (Carlo Erba, Italy) and a Valco injector with a $20-\mu \mathrm{L}$ loop (Valco, Houston, TX). Standard compounds were obtained from Sigma Chemical Co. (St. Louis, MO).

\section{Electrospray Interface}

In the typical electrospray system [15] ions are generated and desolvated at atmospheric pressure and near ambient temperatures (typically $<80^{\circ} \mathrm{C}$ ), by the interaction of a counterflowing bath gas or "sweep gas" with the charged droplets, which are produced by the electrospray. Ideally, the solvent vapor is carried away in the counterflowing gas, and through the action of applied electrical fields the desolvated ions drift to a small sampling orifice or tube where the 
"dry" ions are transmitted directly to the mass analyzer. This conventional interface involves no heating downstream of the sampling aperture. An electrospray system has been described [16] that uses a heated tube $\left(80^{\circ} \mathrm{C}\right.$ ) and carefully controlled collisions between the tube exit and skimmer to desolvate ions. More recently an ion spray system has been coupled to an ion trap mass spectrometer which does not use a counterflowing or curtain gas to assist in the desolvation process [17].

In the system described below, shown schematically in Figure 1, no counterflowing gas is required. The spray is generated as in earlier systems by a high voltage, typically $2.0-2.5 \mathrm{kV}$, applied to a flat tipped hypodermic needle (0.005 in i.d. $\times 0.010$ in $0 . d . \times 0.75$ in long). This needle is connected to stainless steel tubing (1/16 in o.d. $\times 0.005$ in i.d.) by way of a $1 / 16$ to $1 / 32-$ in Valco reducing union and graphite ferrule. This needle assembly is installed in a removable probe with a nylon shaft and an electrically grounded aluminum handle. The liquid effluent enters the probe through a length of fused silica tubing (100 $\mu \mathrm{m}$ i.d. by $30-60 \mathrm{~cm}$ long), which is connected to the stainless steel tubing via another Valco reducing union. The high voltage is connected to the stainless steel tube inside the probe handle, and the system is interlocked so that the high voltage is off whenever the probe is removed from the housing. The nylon probe shaft fits snugly into a stainless steel tube terminated by a converging nozzle, thus maintaining the spray needle in axial alignment with the nozzle aperture. The region between the needle and nozzle is at atmospheric pressure; laboratory air passes freely through the probe and expands through the converging nozzle ( $0.4 \mathrm{~mm}$ diameter) into the furst stage of the vacuum system of the mass spectrometer. This is unlike other electrospray systems which use a flat plate or capillary tube as the connection to the vacuum system. As there is no counterflowing gas, all of the gases and vapors that enter the electrospray chamber must pass through the nozzle into the vacuum system.

The distance between the needle tip and nozzle aperture is adjustable using a knurled nut threaded onto the probe shaft, as illustrated in Figure 1. At flow rates $<-20 \mu \mathrm{L} / \mathrm{min}$, the optimum position for the tip of the needle is usually near the base of the nozzle cone, $\sim 0.9 \mathrm{~cm}$ from its orifice, and a little further back, $\sim 1.5 \mathrm{~cm}$, for higher flow rates $(20-80$ $\mu \mathrm{L} / \mathrm{min}$ ).

Ions passing through the nozzle are transmitted into the mass analyzer via a two-stage momentum separator consisting of a skimmer $(0.6 \mathrm{~mm})$ and ion sampling cone or collimator $(1.0 \mathrm{~mm})$. The skimmer is mounted onto a heated ion source block which is connected to the repeller power supply. The collimator is electrically isolated from the block and the pressure downstream of the collimator is sufficiently low $\left(-10^{-4}\right.$ torr in the source housing) that the collimator potential effectively determines the kinetic energy of the ions transmitted to the quadrupole. The ions are focused into the quadrupole analyzer by using an einzel lens identical to that used with the thermospray source for this instrument. The excess gas and solvent vapor are removed by $200 \mathrm{~L} / \mathrm{min}$ mechanical pumps (Model E2M12, Edwards Vacuum), connected to each stage of the momentum separator.

The distance between the nozzle and skimmer is adjustable by means of an external adjustment screw. This may be optimized while the system is operating, but normally requires adjustment only on initial installation. Typical operating pressures are 3-5 torr for the furst pump out line, 0.14-0.2 torr for the second pump out line (monitored at the top of the mechanical pump), and $2-4 \times 10^{-6}$ torr in the analyzer.

Desolvation is achieved by heating the source block (skimmer-collimator chamber) to temperatures usually associated with thermospray [18], typically 200-250 ${ }^{\circ} \mathrm{C}$. As this chamber is heated, the electrospray spray chamber also heats up due to thermal conduction (to $-90{ }^{\circ} \mathrm{C}$ when the nozzle-collimator chamber has a temperature of $250{ }^{\circ} \mathrm{C}$ ). A water jacket allows the spray chamber temperature to be controlled either by controlling the flow of tap water through the cooling jacket or by using a constant temperature recirculating bath. The temperature of the spray chamber, typically $55-65^{\circ} \mathrm{C}$, is monitored by a thermocouple adjacent to the electrospray needle. Control of the spray chamber temperature was found to be important in handling both organic and aqueous solutions. Earlier electrospray systems encountered difficulty in spraying aqueous buffers unless a sheath solvent [9] or pneumatic nebulization [2] was employed.

The needle, nozzle, skimmer, and collimator are all electrically isolated. Voltages may be applied to each to maximize ion transmission to the detector. The collimator cone is typically set to $10 \mathrm{~V}$ and determines the ion energy at the mass analyzer. The skimmer is electrically connected to the heated block and is tied to the repeller supply which is adjustable from 0 to $200 \mathrm{~V}$ relative to the collimator. Maximum ion transmission typically occurs at a repeller (skimmer) potential between 18 and $25 \mathrm{~V}$. Higher repeller voltages, usually $40-50 \mathrm{~V}$, may be used to cause collisionally induced dissociation (CID) in the region between the skimmer and collimator cones, as discussed below. The nozzle voltage is adjustable from $0-500 \mathrm{~V}$ relative to the skimmer and is usually set at $-250 \mathrm{~V}$. There are several adjustable parameters to optimize, but on a day-to-day basis only the needle voltage needs to be adjusted, in that the needle voltage and ion current may vary with different solvent systems, or when flow rates are changed.

\section{Results and Discussion}

Despite using higher temperatures than other electrospray systems, little or no thermal degradation is 


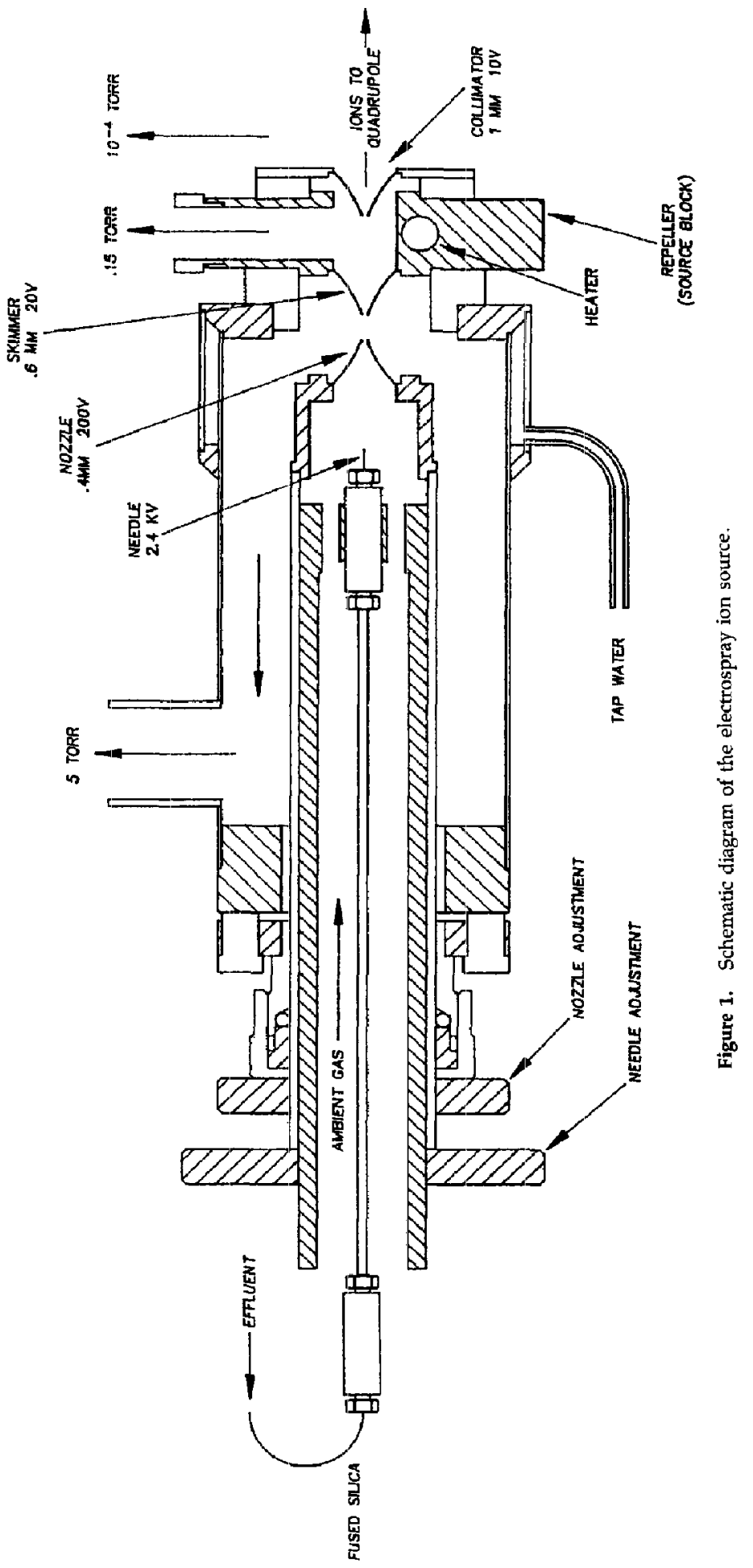


observed. The characteristic multiply charged envelope associated with application of the electrospray technique to proteins such as bovine serum albumin shown in Figure 2, myoglobin, carbonic anhydrase, and cytochrome $C$, is directly comparable to more conventional "cold" systems under similar solvent conditions [3]. As in other electrospray systems the masses of pure proteins such as cytochrome $C$ and carbonic anhydrase can routinely be determined to an accuracy of at least $0.01 \%$. It is perhaps not surprising that multiply charged ions can be desolvated by thermal means without undergoing thermal degradation because multiply charged ions have also been obtained by using a conventional [19] or slightly modified thermospray ion source [20] at conventional LC flow rates $(1.5 \mathrm{~mL} / \mathrm{min})$.

\section{Temperature Studies}

For the electrospray interface described above the dependence of the leucine enkephalin $(\mathrm{M}+\mathrm{H})^{+}$ion intensity on source block and electrospray chamber temperatures are shown in Figure 3 for different solvent compositions. In the electrospray chamber temperature study, the source block was maintained at $250^{\circ} \mathrm{C}$ and in the block temperature study, the spray chamber was maintained, where possible, at $55^{\circ} \mathrm{C}$. However at source temperatures below $180^{\circ} \mathrm{C}$, even with no cooling water, the temperature in the spray chamber dropped below $50^{\circ} \mathrm{C}$, as the chamber is not heated directly but relies on thermal conduction from the source block. The repeller voltage remained unchanged at $20 \mathrm{~V}$, throughout the temperature studies.

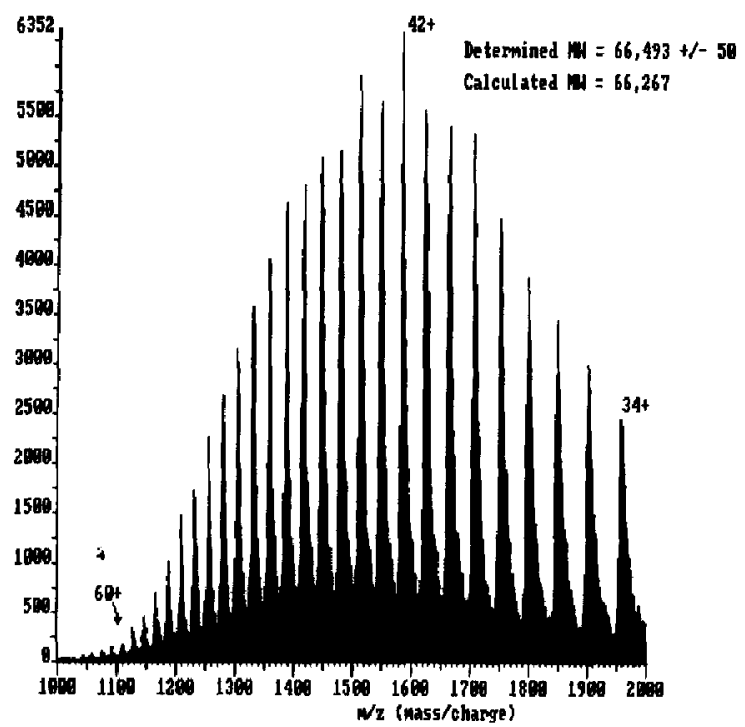

Figure 2. Electrospray spectrum obtained by continuous infusion of bovine serum albumin solution $\left(8 \mathrm{pmol} / \mu_{\mathrm{L}} \mathrm{L}\right.$ in $50: 50$ MeOH: $\mathrm{H}_{2} \mathrm{O}, 2 \%$ acetic acid) at $1 \mu \mathrm{L} / \mathrm{min}$. Spectrum shown is average of five scans at $13 \mathrm{~s}$ per scan.
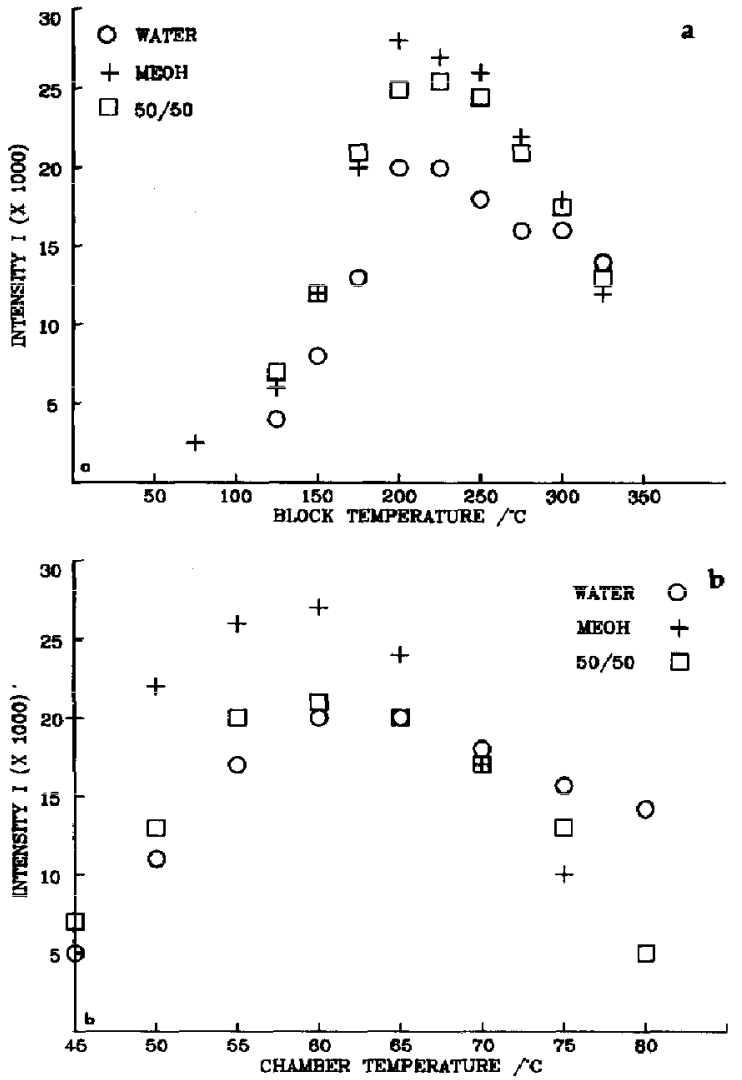

Figure 3. (a) The signal intensity for leucine enkephalin (M + $\mathrm{H})^{+}$ion plotted as a function of source block temperature obtained by continuous infusion of an $89 \mathrm{pmol} / \mu \mathrm{L}$ solution in the specified solvent system ( $+1 \%$ acetic acid), at $5 \mu \mathrm{L} / \mathrm{min}$. Full scan spectra (20-800 u) were acquired at $5 \mathrm{~s}$ per scan. (b) The signal intensity for leucine enkephalin $(\mathrm{M}+\mathrm{H})^{+}$ion plotted as a function of electrospray spray chamber temperature. Other conditions are same as in a.

These results indicate that to obtain maximum signal intensity and stability, a block temperature between 200 and $250{ }^{\circ} \mathrm{C}$, with an associated chamber temperature of $55-65{ }^{\circ} \mathrm{C}$, is optimum for both aqueous and methanolic solutions. It is especially important to maintain the chamber temperature $>50^{\circ} \mathrm{C}$ when spraying aqueous solutions to achieve a stable ion current. At temperatures $>75^{\circ} \mathrm{C}$ signal intensities may be reduced and electrical discharges occur more frequently. Also, when the spray chamber temperature reaches $75{ }^{\circ} \mathrm{C}$ or above, unstable ion currents may result because low boiling point organic solvents begin to vaporize before reaching the end of the electrospray needle. The signal intensity and stability of the electrospray for aqueous or organic solutions is almost independent of chamber temperature between 55 and $65^{\circ} \mathrm{C}$, where stable ion currents are observed.

The temperature dependence of the spectra observed for leucine enkephalin is shown in Figure 4, 
Figure 4. A plot of log signal intensity versus block temperature, for the ions indicated, obtained from the block iemperature study on leucine enikephalin in 50:50 MeOH: $\mathrm{H}_{2} \mathrm{O}$, 1\% acetic acid solution. Other conditions are same as in Figure 3a.

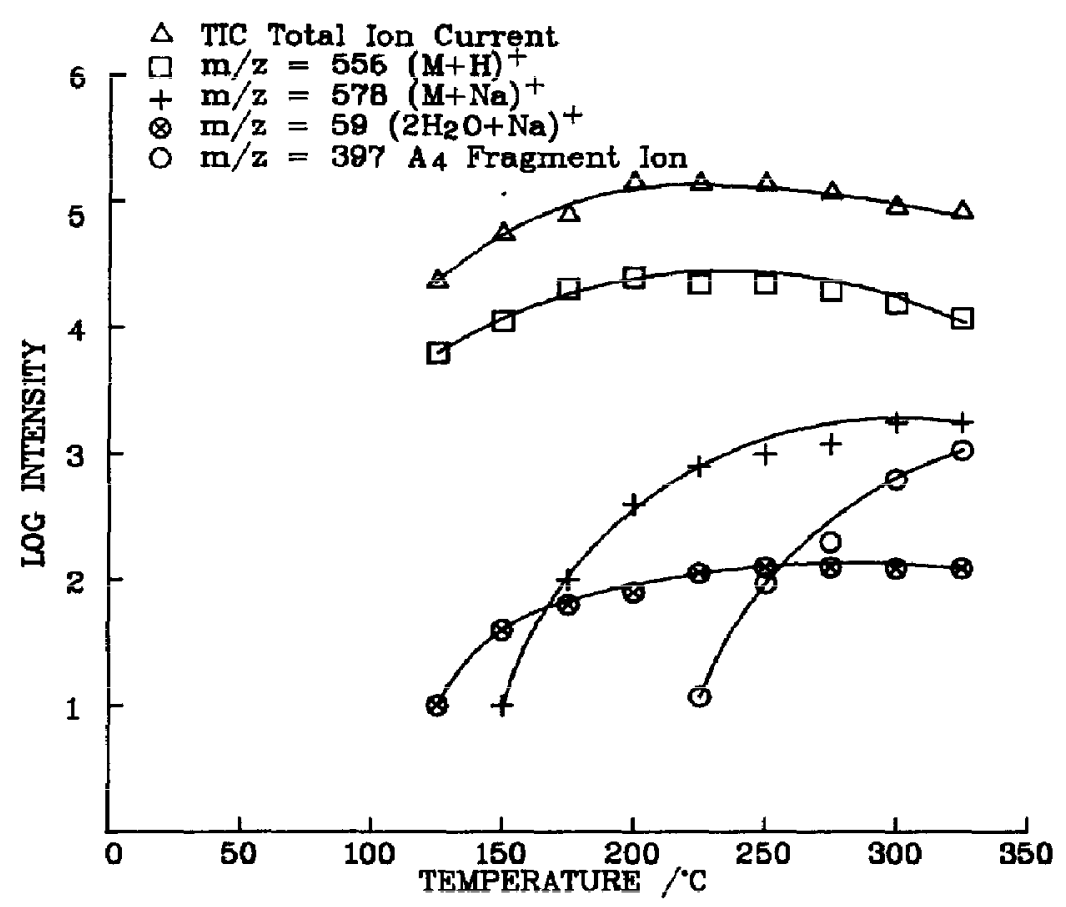

where the logarithms of the intensities of the major ions in the spectra are plotted as functions of source block temperature. The spectrum is dominated by the intense protonated molecular ion $(m / z 556)$ with, as noted above, a broad maximum intensity observed between 200 and $250^{\circ} \mathrm{C}$. Except for small peaks corresponding to solvated sodium, little or no ionization of the solvent is observed. The intensities of these background ions, as well as the $(\mathrm{M}+\mathrm{Na})^{+}$from the sample increase monotonically with increasing temperature. Above $-225{ }^{\circ} \mathrm{C}$ some weak fragment ions are observed whose intensities increase rapidly with increasing temperature; however, at the highest temperature reached in these studies $\left(325^{\circ} \mathrm{C}\right)$ the maximum fragment intensity is $<10 \%$ of the molecular ion. A similar variation in total ion intensity with source block temperature was observed for the multiply charged ions of bovine insulin, with no significant change in the relative intensities of the observed charged states over the range from 150 to $325^{\circ} \mathrm{C}$.

\section{Sensitivity}

Electrically focusing ions at atmospheric pressure is an inherently difficult task [21]. Therefore, aerodynamic focusing inside the electrospray chamber may be a more efficient means of focusing ions at such high pressures. Aerodynamic focusing is achieved in this interface by the ambient gas from the laboratory sweeping ions through the convergent nozzle into the vacuum system. This results in sensitivity which is at least comparable to conventional geometries as illus- trated in Figure 5. This spectrum of cytochrome $\mathrm{C}$ was generated by continuous infusion of solution with only $15 \mathrm{fmol}$ being required to produce the spectrum. However, a total of 2.4 pmol of sample was actually

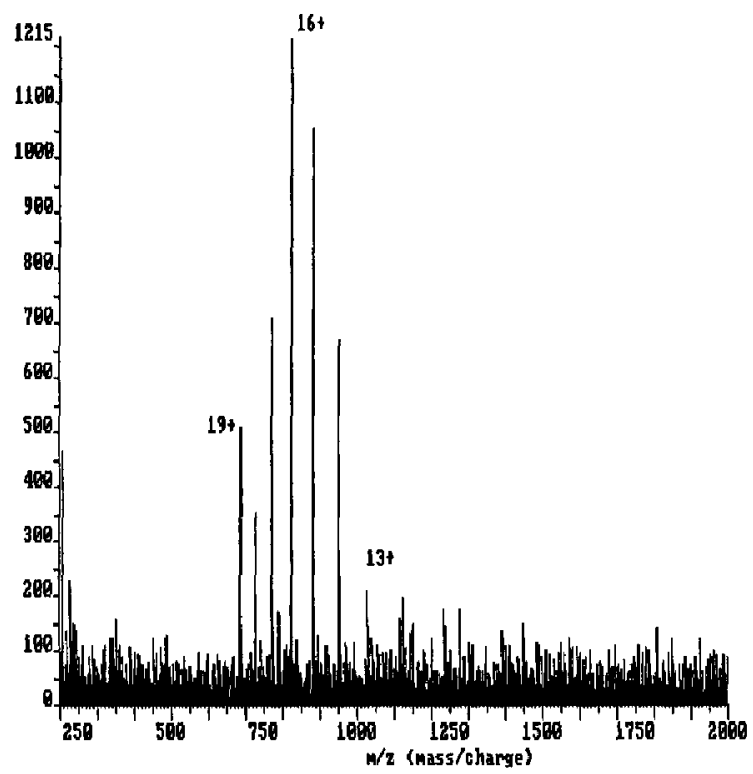

Figure 5. Electrospray spectrum obtained by continuous infusion of a $81 \mathrm{fmol} / \mu \mathrm{L}\left(50: 50 \mathrm{MeOH}: \mathrm{H}_{2} \mathrm{O}, 1 \%\right.$ acetic acid) solution of horse heart cytochrome $C(12,360 \mathrm{u})$, at $1.6 \mu \mathrm{L} / \mathrm{min} ; 15 \mathrm{fmol}$ of sample was consumed during acquisition of this single $7 \mathrm{~s}$ scan. 
used in obtaining this result. The sample was infused at $1.6 \mu \mathrm{L} / \mathrm{min}$ with $30 \mu \mathrm{L}$ of a $0.08 \mathrm{pmol} / \mu \mathrm{L}(50: 50$ $\mathrm{MeOH}: \mathrm{H}_{2} \mathrm{O}, 1 \%$ acetic acid) being loaded into the syringe. During the time the sample was continuously infused, $>100$ spectra similar to that shown in Figure 5 were obtained, and if these are averaged together the signal-to-noise ratio is vastly improved. When sample is not limited, obtaining full-scan spectra $(200-2000 \mathrm{u})$ of sufficient quality to accurately determine the molecular weight of an unknown protein typically consumes 10-100 pmol by continuous syringe pump infusion of $\sim 30 \mu \mathrm{L}$ of sample at concentrations in the $0.5-5 \mathrm{pmol} / \mu \mathrm{L}$ range. When sample is limited, satisfactory results can often be obtained with flow injection of $5 \mu \mathrm{L}$ or less of sample at pmol/ $\mu \mathrm{L}$ concentrations corresponding to total sample consumptions in the 1-10 pmol range.

\section{Dependence on Flow Rate}

Typical results showing the dependence of signal intensity on solvent flow rate and composition are shown in Figure 6 . These results were obtained with continuous infusion of a $6 \mathrm{pmol} / \mu \mathrm{L}$ solution of lysozyme with $1 \%$ acetic acid added to each mobile phase. The results with methanol and 50:50 methanol:water are similar to those observed earlier in conventional electrospray systems [3] in that the maximum sensitivity is observed at the lowest flow rate. For the solvent systems containing $50 \%$ or more organic the signal intensity is essentially independent of flow rate $<\sim 4 \mu \mathrm{L} / \mathrm{min}$, but because the sample input rate is proportional to flow, the sensitivity is actually decreasing with increasing flow. As noted by Fenn et al. [3], the electrospray system behaves as a concentration sensitive detector in this regime. Above $4 \mu \mathrm{L} / \mathrm{min}$ the sensitivity falls off more rapidly with increasing flow rate.

The flow rate dependence with aqueous mobile phases is qualitatively different. The maximum signal intensity for the $9^{+}$ion from lysozyme is observed at a flow rate of $-6 \mu \mathrm{L} / \mathrm{min}$ and the intensity falls off more rapidly at higher flow rates than is the case with the solutions containing $>50 \%$ methanol. The sensitivity for lysozyme (ion current/sample input rate) is nearly constant between 4 and $6 \mu \mathrm{L} / \mathrm{min}$, and vanishes below $\sim 2 \mu \mathrm{L} / \mathrm{min}$. We do not yet fully understand this loss of signal intensity from aqueous solutions at flow rates less than $2 \mu \mathrm{L} / \mathrm{min}$. However, it may be attributed to instabilities in the electrospray process or the solvent delivery system. The signal intensity between 6 and $11 \mu \mathrm{L} / \mathrm{min}$ is essentially independent of solvent composition. In all cases the relative intensities of the different charge states show no appreciable dependence on flow rate. Similar results to these have been obtained on other standard proteins such as cytochrome $C$ and myoglobin which are freely soluble in both water and methanol at these

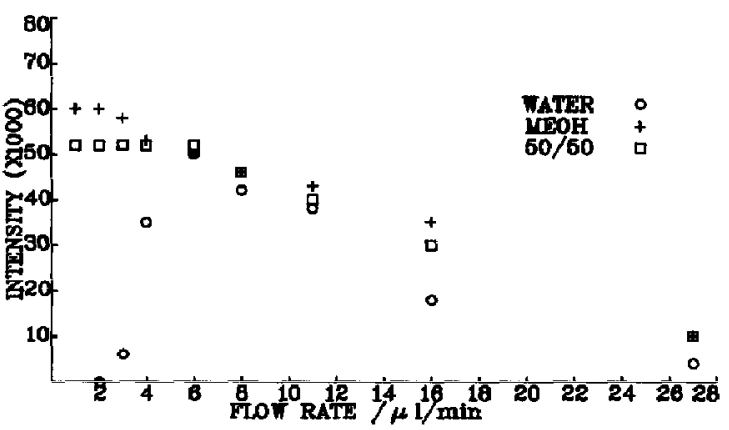

Figure 6. A plot of signal intensity for the $(M+9 H)^{9+}$ ion of lysozyme versus flow rate for the solvent systems shown. No appreciable change in relative intensities of different charge states was observed with flow rate. Results obtained from full scans, $1000-2000 \mathrm{u}$ in $10 \mathrm{~s}$.

concentrations. For example, myoglobin shows similar dependence on flow rate but at optimum flow rate typically gives $\sim 25 \%$ less signal from aqueous solution than from methanol.

This interface can give useful electrospray results at even higher flow rates as shown in Figure 7, where single-ion monitoring results from flow injection of gramicidin $S$ are presented. However, the ability to operate at higher flow rates ( $>40 \mu \mathrm{L} / \mathrm{min}$ ) is very dependent on needle condition; as is the quality of the electrospray spray itself at low flow rates. A poorly cut needle will not allow high flow rates to be achieved. Electrochemically cut needles with smooth, square ends appear to yield the best results. As flow rate is increased, peak area decreases somewhat more rapidly than inversely with flow rate, but peak height decreases more slowly. From these results it appears that the optimum flow rates for on-line chromatography are in the range of $5-10 \mu \mathrm{L} / \mathrm{min}$ where the loss on sensitivity compared to lower flows is compensated by a reduction in band broadening in the flow system.

\section{Ionization Mechanism}

There is no indication that ionization mechanisms are different in this device than in earlier electrospray systems, but the sampling of ions into the mass analyzer is somewhat different. With the skimmer-collimator chamber heated, it is not necessary that solvent vapor be removed prior to entering the vacuum system, as the heat prevents clustering upon adiabatic cooling and also desolvates any ions that are not "dry" on entering the vacuum system through the nozzle orifice. Collisions at high pressures between needle-nozzle and the nozzle-skimmer may also contribute to desolvation as a reduction in temperature $\left(100{ }^{\circ} \mathrm{C}\right.$ block temperature) does not result in an increase of solvent adducts, but only reduces the 
Figure 7. A plot of peak area $(x)$ and peak height (o) versus flow rate, calculated from the total ion chromatogram from single-ion monitoring of the $(\mathrm{M}+2 \mathrm{H})^{2+}$ ion of gramicidin s; $0.44 \mathrm{pmol}$ was injected into a flowing stream of 50:50 acetonitrile: $\mathrm{H}_{2} \mathrm{O}, 0.01 \%$ trifluoroacetic acid, at the flow rates indicated.

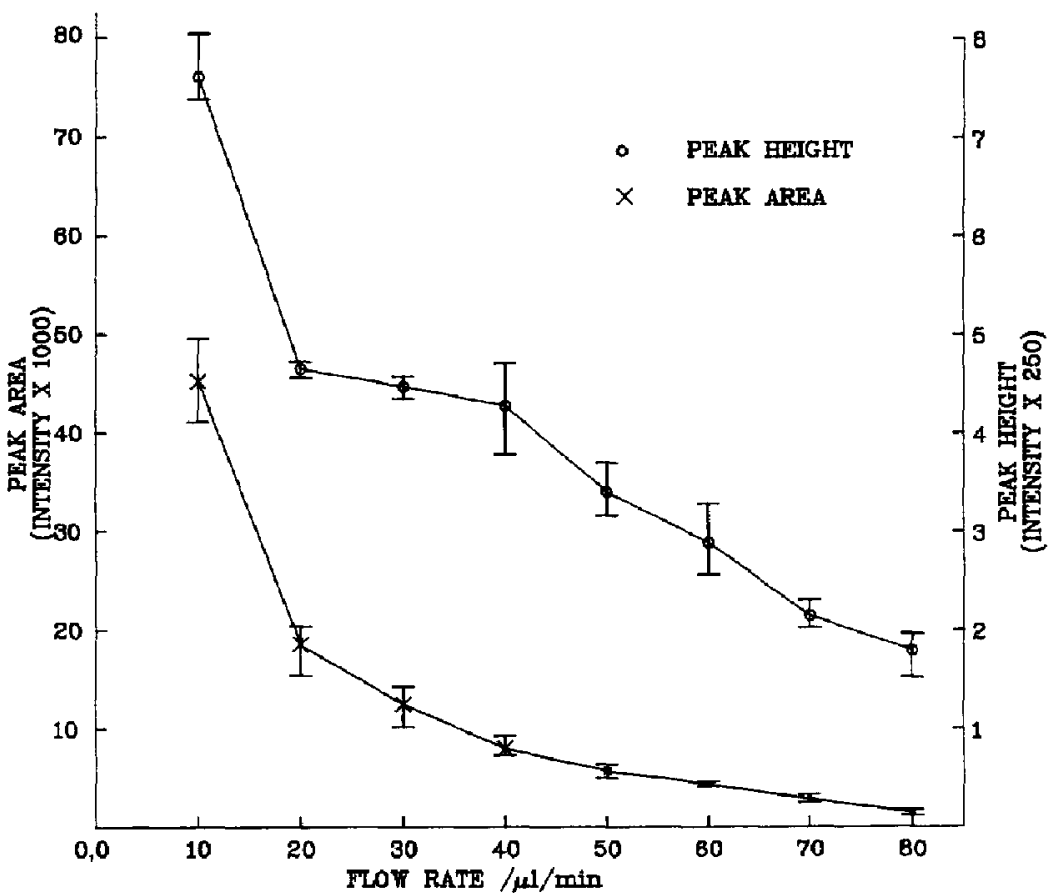

intensities of the protonated species. Also, only a small amount of fragmentation occurs even on increasing the source temperature to $325^{\circ} \mathrm{C}$.

\section{Protein and Glycoprotein Analysis}

Several samples have been encountered which do not yield useful results in methanol, and give only weak spectra in 50:50 methanol:water mobile phases. In most cases these are samples for which results have not been reported in the earlier electrospray literature. We have found that many of these give excellent results in aqueous mobile phases. One example of these samples are bacterial proteases such as thermolysin (Bacillus thernoproteolticus rokko) and subtilisin Carlsberg (Bacillus subtilis), a bacterial alkaline protease enzyme that has widespread use in laundry detergents. These species have very stable, tight tertiary structures with the basic protonation sites being difficult to penetrate. However, spectra were readily obtained from aqueous solutions of such species, as shown in Figure 8, possibly due to the relaxation of the tertiary structure in aqueous solution. Also the measured molecular weight $(27,290.1 \pm 3 u)$ is in good agreement with the value calculated from the known sequence $(27,288.4 \mathrm{u})$. However, the signal intensity was weaker in 50:50 water:methanol and we were unable to obtain molecular weights on these samples in methanol.

The results from a more detailed study of the effects of different solvent systems and spray chamber temperature on the electrospray ionization of a number of proteins and glycoproteins, such as proteinase $\mathrm{K}$ and ribonuclease $\mathrm{B}$, will be published elsewhere.

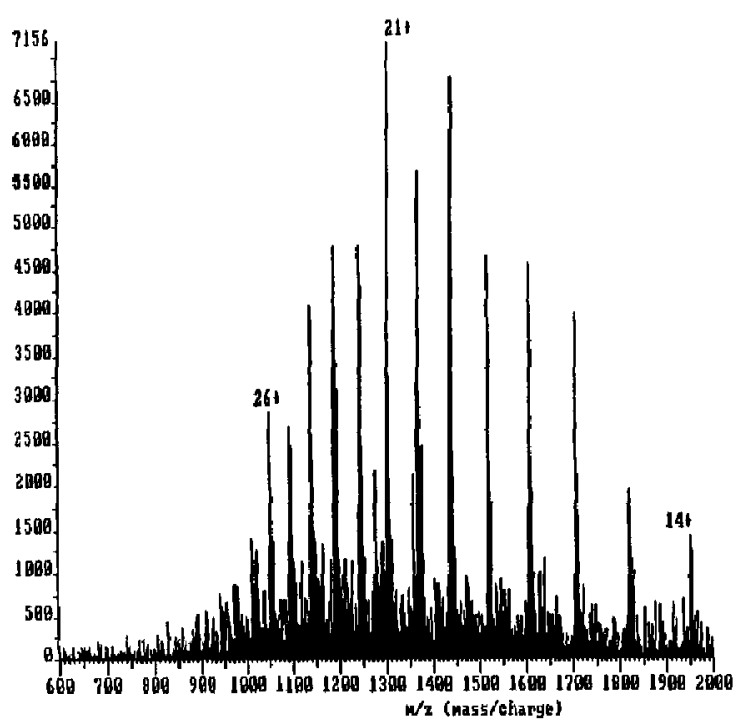

Figure 8. Electrospray spectrum obtained by continuous infusion of a 22 pmol $/ \mu \mathrm{L}$ solution of subtilisin Carlsberg (Bacillus subtilis) in aqueous $5 \%$ acetic acid, at $5 \mu \mathrm{L} / \mathrm{min}$. Spectra were acquired at $7 \mathrm{~s}$ per scan, and spectrum shown is an average of three scans; $38.5 \mathrm{pM}$ was used to generate spectrum. 


\section{Fragmentation}

Electrospray is a soft ionization technique which provides information on molecular weight. However, the ability to selectively fragment ions can be a powerful tool for extracting structural information. This capability with electrospray ionization has been well demonstrated on triple quadrupole systems [22, 23]. CID in the high pressure nôzzlè-skimumer or túbe exitskimmer region of single quadrupole electrospray systems has also been reported $[24,25]$ as well as in the ion acceleration region of magnetic sector instruments [26].

In the electrospray system described in this article it is possible in some cases to obtain both molecular and fragment ions by changing the repeller (skimmer) voltage relative to the collimator. By increasing the repelier to colilimator voltage from 20 to $-40 \mathrm{~V}$, CID can be observed. Examples of typical results are shown in Figures 9 and 10. For proteins with a large number of charges, such as myoglobin in Figure $\dot{9}$, the major effect appears to be deprotonation of multiply charged ions causing the multiply charged envelope to shift toward lower charge states on increasing the repeller voltage. For small peptides where singly and doubly charged ions predominate, such as leucine enkephalin in Figure 10, sequence information can often be obtained merely by changing the repeller voltage. The degree of fragmentation is compound dependent but in a number of cases has been comparable to that obtained from a daughter ion spectrum of the protonated molecular ion in a triple quadrupole system. In general, the total ion current maximizes at a repeller voltage of $\sim 20 \mathrm{~V}$, apparently due to ion focusing effects. Increasing the repeller to $40 \mathrm{~V}$ tends to defocus the ion beam in addition to producing fragmentation. As a consequence some loss in total sensitivity accompanies use of the repeller to obtain structural information.

Unlike other electrospray systems, increasing the voltage on the nozzle relative to the first skimmer has little effect on the mass spectrum in terms of fragmentation or shifting the multiply charged envelope [27]. This is probably because the pressure in this region is rather higher in our system (owing to the relatively larger nozzle aperture used) than in the earlier systems using single-stage pumping. As a result the ions do not gain sufficient energy between collisions for efficient activation until the applied voltage difference approaches the threshold for discharge. On the other hand, the pressure in the skimmer-collimator region where the repeller voltage is applied is rather lower than in the region where collisional activation was observed in earlier systems; thus CID can be observed at relatively lower voltage differences applied here.

\section{Conclusion}

The electrospray system described here is relatively simple in design and easy to use. Heating the electro-
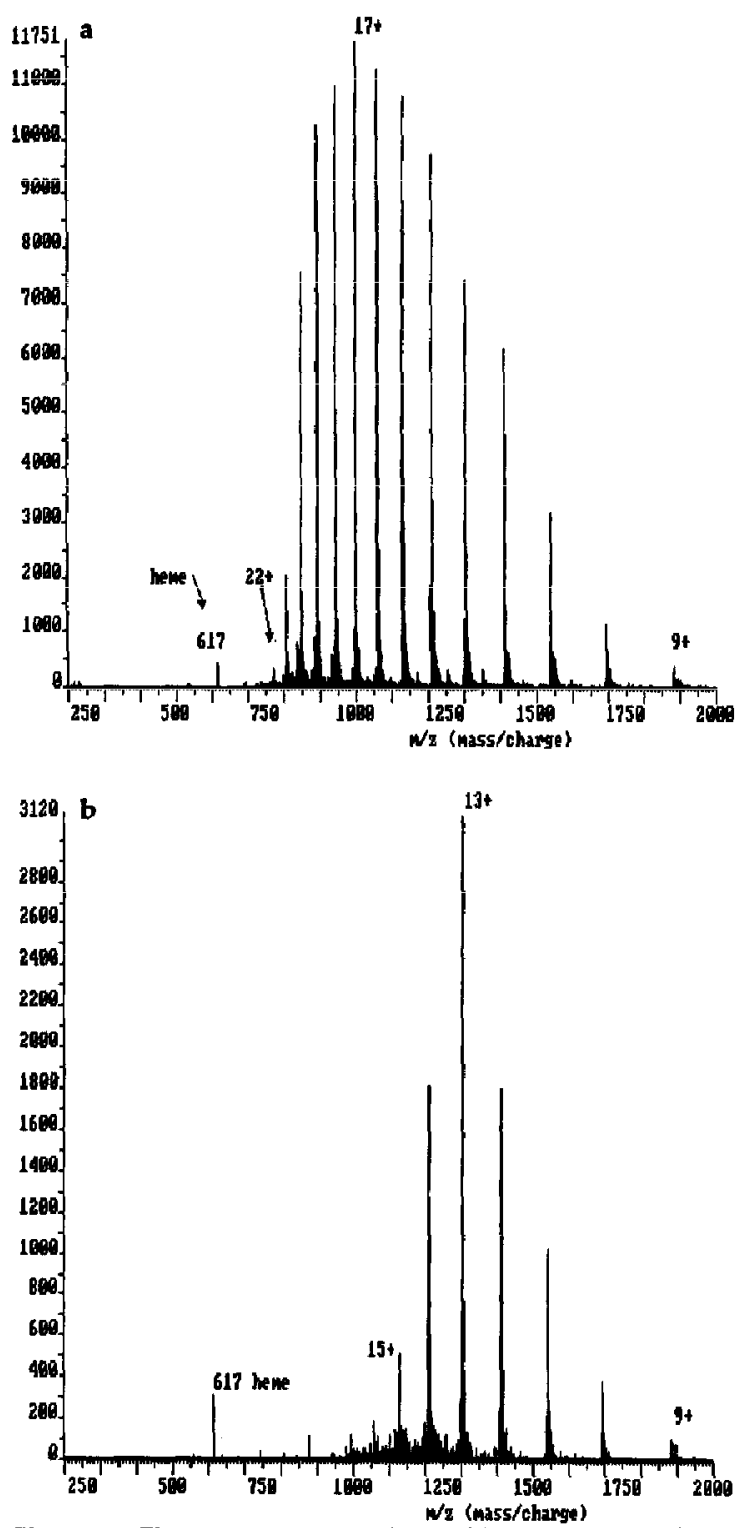

Figure 9. Electrospray spectra obtained by continuous infusion of a $0.5 \mathrm{pmol} / \mu \mathrm{L}$ solution of horse heart myoglobin $(16,951 \mathrm{u})$ in 50:50 MeOH: $\mathrm{H}_{2} \mathrm{O}, 1 \%$ acetic acid, at $3 \mu \mathrm{L} / \mathrm{min}$. Spectra acquired at $7 \mathrm{~s}$ per scan, spectra shown are three scan averages; 0.5 pmol was consumed. Spectra were acquired under identical conditions except for the change in repeller voltage; (a) repeller at $20 \mathrm{~V}$; (b) repeller at $40 \mathrm{~V}$.

spray interface does not cause significant thermal degradation, but does enable aqueous solutions to be electrosprayed and increased flow rates to be accommodated. The sensitivity is generally comparable to that obtained with earlier approaches, and accurate molecular weight determinations of peptides, proteins, and glycoproteins can usually be obtained by using low picomole quantities of sample. In addition, 

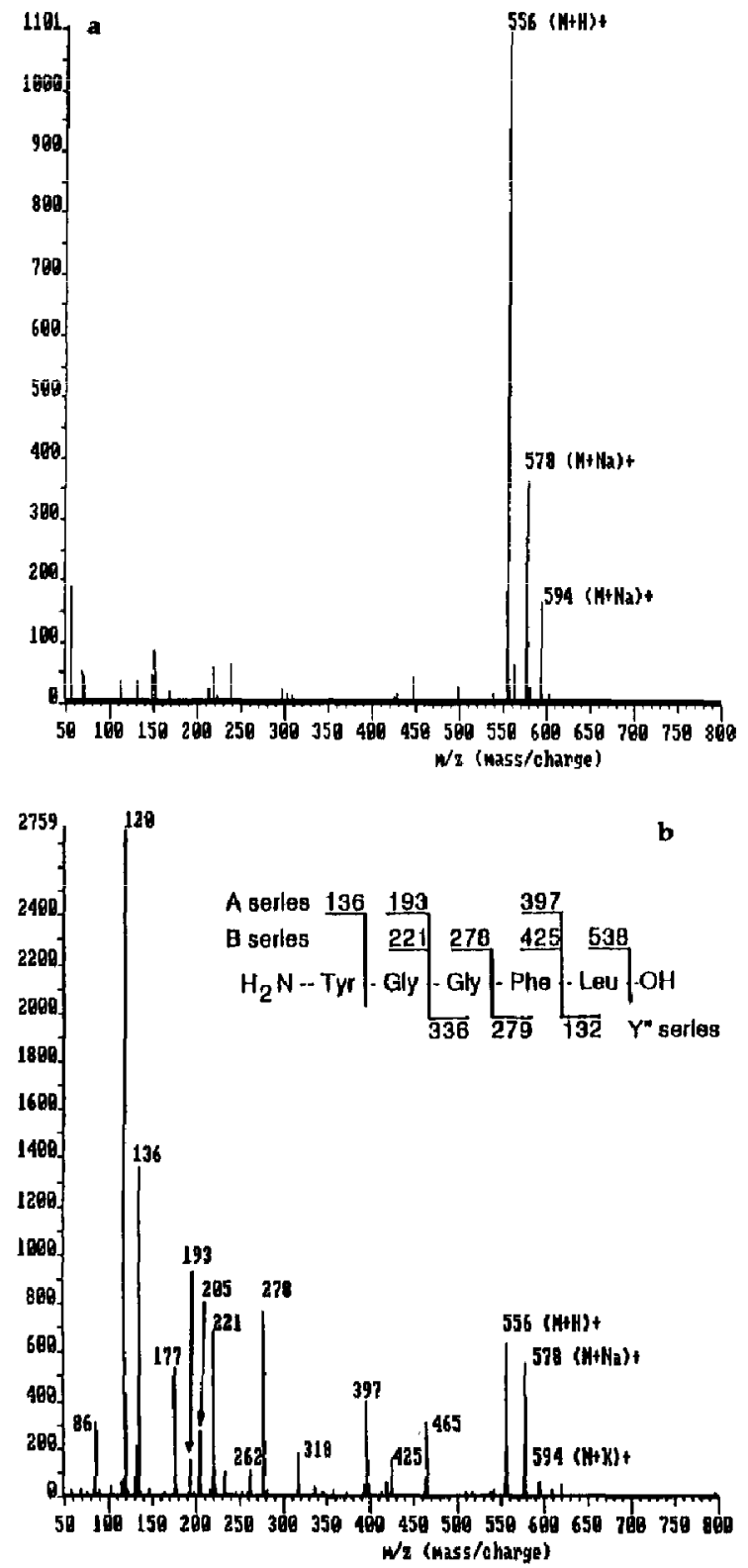

Figure 10. Electrospray spectra obtained by continuous infusion of an $89 \mathrm{pmol} / \mu \mathrm{L}$ solution of leucine enkephalin in 50:50 $\mathrm{MeOH}: \mathrm{H}_{2} \mathrm{O}$ at $10 \mu \mathrm{L} / \mathrm{min}$. Single 5-s scans shown. Both spectra were acquired under identical conditions except for the change in repeller voltage; (a) repeller at $20 \mathrm{~V}$; (b) repeller at $40 \mathrm{~V}$.

CID can be selectively employed to give some structural information from relatively low molecular weight compounds.

\section{Acknowledgment}

Partial support for this research by the Department of Health and Human Services under a Small Business Innovation Re- search (SBIR) grant, Number 1 R43 GM44466-01 is gratefully acknowledged.

\section{References}

1. Meng, C. K.; Mann, M.; Fenn, J. B. Proceedings of the 36th Annual Conference on Mass Spectrometry and Allied Topics, 1980; $\mathrm{pp} 771-772$

2. Covey, T. R.; Bruins, A. P.; Henion, J. D. Org. Mass Spectrom. 1988, 23, 178-186.

3. Fenn, J. B.; Mann, M.; Meng, C. K.; Wong, S. F.; Whitehouse, C. M. Mass Spectrom. Rev. 1990, 9, 37-70.

4. Smith, R. D.; Loo, J. A.; Edmonds, C. G.; Barinaga, C. J.; Udseth, H. R. Anal. Chem. 1990, 62, 882-899.

5. Huang, E. C.; Wachs, T.; Conboy, J. J.; Henion, J. D. Anal. Chem. 1990, 62, 713A-725A.

6. Mann, M. Org. Mass Spectrom. 1990, 25, 575-587.

7. Mann, M.; Meng, C. K.; Fenn, J. B. Anal. Chem. 1989, 61. $1702-1708$.

8. Covey, T. R.; Bonner, R. F.; Shushan, B. I.; Henion, J. D. Rapid Commun. Mass Spectrom. 1988, 2, 243-246.

9. Smith, R. D; Barinaga, C. J.; Udseth, H. R. Anal. Chem. 1988, 60, 1948-1952.

10. Lee, E, D.; Henion, J, D.; Covey, T, R. J. Microcol, Sep $1989,1,14-18$.

11. Huang, E. C.; Henion, J. D. J. Am. Soc. Mass Spectrom. 19990, $1, \overline{1} 5 \overline{8}-165$.

12. Allen, M. H.; Lewis, I. A. S. Rapid Commun. Mass Spectrom. 1989, 3, 255-258.

13. Yamashita, M.; Fenn, J. B. J. Phys. Chern. 1984, 88, 4451-4459.

14. Allen, M. H.; Field, F, H.; Vestal, M. L. Proceedings of the 38th Annual Conference on Mass Spectrometry and Allied Topics, 1990; pp 431-432.

15. Whitehouse, C. M.; Dreyer, R. N.; Yamashita, M,; Fenn, J. B. Anal. Chem. 1985, 57, 675-679.

16. Chowdhury, S. K.; Katta, V.; Chait, B. T. Rapid Commun. Mass Spectrom. 1990, 4, 81-87.

17. Van Berkel, G. J.; Glish, G.; McLuckey, S. A. Anal. Chem. 1990, 62, 1284-1295.

18. Vestal, M. L.; Fergusson, G. J. Anal. Chem. 1985, 57, 2373-2378.

19. Straub, K.; Chan, K. Rapid Commun. Mass Spectrom. 1990, 4, $267-271$.

20. McLean, M. A.; Vestal, M. L.; Vestal, C. H; Allen, M. H.; Field, F. H. Proceedings of the 38th Annual Conference on Mass Spectrometry and Allied Topics, 1990; pp 1138-1139.

21. Busman, M.; Sunner, J; Vogel, C. R. I. Am. Soc. Mass Spectrotr. 1990, 2, 1-10.

22. Covey, T. R.; Conboy, J. J.; Henion, J. D. Praceedings of the 37th Annual Conference on Mass Spectrometry and Allied Topics. 1989; pp 905-906.

23. Barinaga, C. J.; Edmonds, C. G.; Udseth, H. R.; Smith, R. D. Rapid Commun. Mass Spectrom. 1989, 3, 160-164.

24. Smith, R. D.; Loo, J. A,; Barinaga, C. J.; Edmonds, C. G.; Udseth, H. R. I. Am. Soc. Mass Spectrom. 1990, 1, 53-65.

25. Katta, V.; Chowdhury, S. K.; Chait, B. T. Amal. Chem. 1991, 63, 174-178.

26. Meng, C. K.; McEwen, C. N.; Larsen, B. S. Rapid Commun. Mass Spectrom. 1990, 4, 151-155.

27. Loo, J. A.; Udseth, H. R.; Smith, R. D. Rapid Cummun. Mass Spectrom. 1988, 2, 207-210. 